\title{
RBEP
}

\section{O que é "desenvolver o raciocínio lógico"? Considerações a partir do livro Alice no país das maravilhas}

Denise Silva Vilela

Deiziele Dorta

\section{Resumo}

Estabelece relações entre temas das áreas de filosofia da lógica e educação matemática, com a finalidade de promover reflexões pedagógicas sobre um dos objetivos do ensino da matemática em todos os níveis: "desenvolver o raciocínio lógico" dos estudantes. O propósito é percorrer, por meio de cenas da história de Alice no país das maravilhas, alguns modos de pensar, entre os quais está o pensamento lógico. Esta obra de Lewis Carroll possui uma grande riqueza tanto de apelos lógicos, mediante os quais explicitamos princípios e regras da lógica clássica, como também de coisas sem lógica e fantásticas, que evidenciam aqui a importância da criatividade e da fantasia no desenvolvimento integral da criança.

Palavras-chave: desenvolvimento do raciocínio; lógica clássica; educação infantil; ensino das séries iniciais. 


\section{Abstract \\ What does it mean to develop logical thinking? Considerations from the book Alice in Wonderland}

The present article establishes relations among themes of the areas of Philosophy of Logic and Mathematics Education with the purpose of promoting pedagogical reflections about the aims of Mathematics in all levels: to develop the student's logical reasoning. The purpose is to identify different ways of thinking, such as logical reasoning, through scenes from Alice in Wonderland. This work of Lewis Carroll has great richness not only concerning logical appeals, in which we explicit principles and rules of classical logics, but also concerning things without logic that are fantastic and show the importance of creativity and fantasy to child development.

Keywords: thinking development; classical logics; early childhood education; early years teaching.

Como que atendendo ao pedido da garota, o Gato vai desaparecendo lentamente da cauda até o sorriso, restando o sorriso sem rosto.

(Carroll, 1980, p. 84).

\section{Apresentação}

O presente texto tem o intuito de explicitar princípios e regras da lógica clássica, no contexto de uma obra da literatura infantil, Alice no país das maravilhas. Sua análise permite-nos uma compreensão crítica desses princípios no que diz respeito a objetivos frequentes do ensino de matemática e a orientações pedagógicas que frisam a importância de desenvolver o raciocínio lógico:

O desafio que se apresenta é [...] apontar em que medida os conteúdos contribuem para o desenvolvimento intelectual do aluno, ou seja, para a construção e coordenação do pensamento lógico-matemático, para o desenvolvimento da criatividade, da intuição, da capacidade de análise e de crítica, que constituem esquemas lógicos de referência para interpretar fatos e fenômenos. 
Embora nestes Parâmetros a Lógica não se constitua como um assunto a ser tratado explicitamente, alguns de seus princípios podem e devem ser integrados aos conteúdos, desde os ciclos iniciais, uma vez que ela é inerente à Matemática. No contexto da construção do conhecimento matemático é ela que permite a compreensão dos processos; é ela que possibilita o desenvolvimento da capacidade de argumentar e de fazer conjecturas e generalizações, bem como o da capacidade de justificar por meio de uma demonstração formal. (Brasil, 1998a, p. 49).

O livro Alice no país das maravilhas, escrito por Charles L. Dogson (1832-1898), que usou o pseudônimo Lewis Carroll para assiná-lo, foi selecionado por ser rico em detalhes e ter reconhecida qualidade de penetrar tanto em aspectos lógicos como de fantasia. O autor, que atuou como professor de matemática na Universidade de Oxford por vários anos e como matemático, lógico e romancista, atrela conceitos de lógica ao mundo de fantasia criado no sonho de Alice. Ele imprime à obra fortes características da lógica; propicia reflexões sobre ela, na medida em que articula tanto os princípios e as regras da lógica como as contradições e os argumentos circulares; permite-nos ver dificuldades do conceito de identidade; desenvolve argumentos em que se podem identificar silogismos e falácias; e, até mesmo, expressa o seu gosto pelos paradoxos e pelo nonsense, esbarrando nos limites da linguagem. "Assim, um dos traços característicos da lógica de Charles Dodgson é o poder de forçar as leis da lógica, explorar os limites da linguagem simbólica, mostrar os limites das formulações, no fundo, revelar o nonsense que pode estar escondido sob a aparência da correção formal" (Pinto, 2009, p. 2).

Desse modo, o estudo e a análise da obra são interessantes para uma compreensão ampla da lógica, ainda que inicial, na medida em que ela apresenta diversos conceitos dessa área de conhecimento e, ao mesmo tempo, nega, contradiz, altera ou brinca com eles. Esse recurso de alternar características que são da lógica e as que não são possibilita uma visão complementar a apresentações sistemáticas e diretas, exclusivamente afirmativa do assunto. Para o educador matemático, é de grande valor conhecer os limites e as possibilidades do pensamento lógico dentro da linguagem humana, pois é inerente à prática do professor disciplinar o pensamento do aluno. Entendemos, levando em conta a noção de cultura escolar, que a escola não apenas transmite conteúdos científicos como também possui aspectos disciplinadores mais amplos; é um meio de aculturação, de imposição de regras e formas de pensamento (Chervel, 1990, p. 184).

Tomamos como referência uma concepção de infância que valoriza o desenvolvimento integral da criança em seus aspectos sociais, culturais, intelectuais, psicológicos e físicos; que a considera um período próprio da vida, e não um período de preparação para o futuro:

Cada idade não está em função de outra idade. Cada idade tem, em si mesma, identidade própria, que exige uma educação própria, uma realização própria enquanto idade e não enquanto preparo para uma outra idade. [...] Cada fase da idade [...] tem que ser vivida na totalidade dela mesma e não ser submetida a futuras vivências [...]. (Arroyo, 1995, p. 19). 
A ideia de escola tomada como referência é aquela que dá condições de desenvolvimento para todas as dimensões da pessoa no presente (Arroyo, 1995, p. 21). Entendemos que, assim como o desenvolvimento não deve ser impedido, com a mesma ênfase, ele não deve ser forçado. Nessa medida, os compromissos e a formação intelectual devem ser dosados com as necessidades de brincar, fantasiar, criar livremente. Especificamente, a matemática como disciplina escolar deve ser compreendida tanto por sua base lógica quanto por suas relações com a linguagem natural. Dessa maneira, a educação infantil e o ensino fundamental podem valorizar o desenvolvimento integral do estudante, sendo importante trabalhar a criticidade, a criatividade, o raciocínio lógico e a capacidade de refletir.

O objetivo deste artigo, portanto, é entender o que é "desenvolver o pensamento lógico" dentro de uma compreensão de desenvolvimento integral do estudante; assim, este trabalho é precisamente de lógica, filosofia da lógica e educação matemática. A partir de uma análise da obra de Carroll, realizada por categorias extraídas da lógica clássica (Dorta, 2009), procuramos responder questões da educação matemática, como: "Que tipo de raciocínio a matemática desenvolve?". A proposta vai ao encontro do questionamento da ideia de "racionalidade natural" apresentado por Gottschalk (2008, p. 83), já que enfatizamos que os princípios lógicos não são óbvios, isto é, a relação deles com a língua natural e cotidiana é específica e exige um aprendizado. A intenção é trazer à tona reflexões sobre um tema estrutural da matemática escolar - raciocínio lógico -, mostrando, por meio de cenas da história de Alice, alguns modos de pensar, entre os quais está o pensamento lógico.

Apresentamos, em seguida, uma discussão centrada nos três princípios da lógica: o da identidade, o da não contradição e o do terceiro excluído. A análise da obra possibilita ainda entender o que são silogismo, inferência válida e falácia. Essa discussão tem como referências centrais Shibles (1974) e Machado e Cunha (2005).

\section{Lógica: aspectos históricos e conceituais}

O termo "lógica" está sendo empregado aqui como lógica formal, uma área do conhecimento que trata dos conceitos, dos juízos e dos raciocínios, que independem de seu conteúdo, tal como desenvolvido pelo filósofo grego Aristóteles (384-322 a.C.).

A primeira sistematização dessa lógica, chamada clássica, realizada por Aristóteles, baseia-se nos três princípios que regem as leis formais do pensamento lógico:

- Princípio da identidade - cada coisa é igual a si mesma; em símbolos: $(A=A)$.

- Princípio da não contradição - algo não pode ser e não ser ao mesmo tempo; em símbolos: $\neg(\mathrm{A} \wedge \neg \mathrm{A})$. 
- Princípio do terceiro excluído - uma proposição é verdadeira ou falsa e não existe terceira opção; em símbolos: $(A \vee \neg A){ }^{1}$

A partir desses princípios, Aristóteles estruturou o silogismo, composto por duas proposições e uma conclusão que, seguindo as regras, conduzem a uma inferência válida: de premissas verdadeiras obtêm-se conclusões verdadeiras. As proposições são frases estruturadas de tal modo que possam ser classificadas somente como verdadeiras ou falsas. As regras dos silogismos ficaram conhecidas por meio das figuras dos silogismos e de uma série de normas que acompanhavam tais figuras. Na Idade Média, as regras foram reeditadas pelo que ficou conhecido como modus tolens e modus ponens, explicitados adiante. De fato, esses princípios e a relação da lógica com a argumentação permaneceram e sofreram alterações não significativas para nossos propósitos até o final do século 19, quando Frege (1848-1925), na elaboração dos Fundamentos da aritmética (1884), empregou símbolos que são o marco inicial da lógica matemática ou simbólica.

O projeto de Frege de encontrar os fundamentos seguros para a aritmética foi realizado mediante a tentativa de definir a noção de número a partir dos princípios da lógica, expressa no subtítulo de sua obra Fundamentos da aritmética: uma investigação lógico-matemática do conceito de número. Bertrand Russel (1872-1970) identificou paradoxos nas formulações de Frege, o que, por um lado, comprometeu absolutamente o projeto deste e, por outro, propiciou estudos que resultaram na formulação de outras lógicas denominadas "lógicas não clássicas", pois alteram os princípios consolidados nesse campo do conhecimento. Nessa ocasião, "a história duplamente milenar da lógica começou a mudar [...]. No momento ela versa sobre determinadas estruturas abstratas, que podemos denominar de sistemas lógicos, análogos, em espírito, às estruturas da álgebra ou de outros ramos da matemática" (Costa, 2002, p. 1).

As chamadas lógicas não clássicas podem ser divididas basicamente em duas espécies: as complementares e as heterodoxas. As complementares respeitam as regras e os princípios da lógica clássica, apenas inserindo alguns novos operadores, de maneira a completar sua linguagem. Já as heterodoxas questionam e negam a lógica clássica, surgem com a intenção de substituí-la.

As lógicas heterodoxas, nas quais não vale a lei reflexiva da identidade, são chamadas lógicas não-reflexivas. [...]. Nas lógicas paracompletas não é válido o princípio do terceiro excluído, ou seja, pode existir fórmula A tais que nem A e nem a negação de A não são teoremas. O princípio da não-contradição é derrogado nas lógicas relevantes e na maioria das lógicas paraconsistentes. (D’Ottaviano, Feitosa, 2009, p. 22).

Serão consideradas a estrutura da argumentação e as definições do cálculo proposicional de primeira ordem da lógica clássica, numa linguagem intermediária entre a da matemática e a da argumentação, que visa à compreensão inicial do assunto sem pressupor conhecimentos

\footnotetext{
$\overline{{ }^{1} \text { Esclarecemos que, em ge- }}$ ral, as proposições serão aqui representadas por letras maiúsculas e os símbolos que empregamos são: NÃO: $\neg$

IMPLICAÇÃO: $=>$

$\mathrm{E}: \wedge$

OU: $\vee$
} 
específicos de matemática ou lógica. Porém não serão observadas as necessidades formais que um curso de lógica demanda, pois o propósito é apenas mencionar temas específicos da lógica enunciados ao longo da narrativa de cenas da história.

O interesse em mencionar os desenvolvimentos da lógica deve-se, na presente abordagem, à possibilidade de perceber a importância e as dimensões de seus princípios em todo seu desenvolvimento e na sua relação específica com a matemática. É, pois, a alteração, a eliminação ou a substituição desses princípios que promove desenvolvimentos significativos no campo da lógica, tal qual ocorreu com as geometrias não euclidianas.

Devemos esclarecer ainda que a lógica aristotélica, em contraposição à simbólica, desenvolve uma fusão com a linguagem, dentro dos argumentos. Para Aristóteles, a dedução, composta dos princípios e das regras em questão, é um dos modos de conhecer mais seguro que outros, como a intuição e a indução, pois, na dedução, a conclusão já está contida nos enunciados: indica um desdobramento deles. É por isso que, no contexto da lógica aristotélica, podemos facilmente entender o que é sofisma ou falácia: é um argumento apenas aparentemente correto; mas, quando analisado do ponto de vista dos princípios e das regras, não o é.

As relações entre matemática e lógica estão evidentes desde a sistematização da matemática realizada por Euclides, no século 3 a. C., que utilizou os princípios e as regras da lógica aristotélica para organizar de forma axiomático-dedutiva os conteúdos matemáticos que já eram conhecidos na ocasião (Vilela, 1996, p. 132).

Apresentamos, a seguir, uma discussão centrada nos três princípios da lógica e nas regras de dedução que estruturam os silogismos no contexto da obra Alice no país das maravilhas.

\section{Discussão dos princípios da lógica clássica em Alice no país das maravilhas}

Alice no país das maravilhas inicia-se com a menina Alice entediada com um livro que, por não ter figuras ou diálogos, torna-se desinteressante. Dessa maneira, o autor expressa que a linguagem infantil inclui figuras, desenhos e conversas, e não apenas palavras.

Bem diferente da vida enfadonha que tem, Alice, em seguida, passa por uma série de acontecimentos que quebram as regras do real e mergulham o leitor em um mundo de grande fantasia.

\section{Discussão do princípio da identidade em Alice no país das maravilhas}

Sabemos que Alice vive suas aventuras enquanto sonha, ou seja, em estado inconsciente, e que todos os fatos acontecem numa diferente 
condição de espaço e tempo. Assim, o livro vai além do real, já que a personagem passa por situações de sonho e age entre sua vida normal e os absurdos do mundo onírico.

No universo psicológico ou emocional, é frequente a discussão sobre a identidade e a subjetividade, que aparentemente não tem relação com a discussão que a matemática pode fazer deste seu princípio fundante e absolutamente óbvio: o da identidade A=A. Propor esse debate é tarefa da filosofia da lógica, aqui colocada com o intuito de realizar esclarecimentos no âmbito da educação. A ideia não é tentar encontrar identidades entre esses usos da psicologia e da matemática, mas percorrer diferentes usos, a fim de relativizar visões predominantes, apresentar outro modo, ver de outras maneiras (cf. Wittgenstein, 1991, § 144, p. 64), num propósito de ampliar a compreensão sobre o tema. Particularmente, na educação matemática, trazemos à tona o questionamento da ideia de "racionalidade natural" apresentada por Gottschalk (2008, p. 83), enfatizando que os princípios lógicos não são óbvios, sobretudo no início da escolaridade, até que tenham sido suficientemente aprendidos.

Logo no início da história aparece o primeiro traço nonsense, que permanecerá ao longo da trama: um coelho branco passa correndo e murmurando que está atrasado, enquanto confere as horas em um relógio de bolso. Coelho atrasado, olhando o relógio - eis um fato que não faz parte de nossa realidade; trata-se de um acontecimento, para nós, "sem sentido", se analisado do ponto de vista real, mas natural em uma história infantil, um sonho, um estado de inconsciência.

Alice, curiosa, segue o coelho e entra em uma toca que a leva a cair numa espécie de túnel, que pode ser considerado um rito de passagem, como se a menina estivesse saindo da vida real para entrar em um mundo de fantasia e do sonho.

Ao longo da queda, Alice segue um gato e, ao cair, vê-se numa sala cheia de portas trancadas em que apenas uma, de 40 centímetros, ela conseguiria abrir. Foi então que, pela primeira vez, Alice alterou seu tamanho, tomando o líquido de uma garrafa com o rótulo Beba-me, que a fez diminuir. Estaria aquela garrafa ali antes do desejo de Alice de passar pela porta? Ou teria aparecido mediante sua vontade? Durante esse acontecimento, a menina percebe que as regras que conhece não regem os acontecimentos naquele lugar. Mas os princípios da lógica permanecem? Especificamente: como fica, nesta situação, o princípio da identidade? Aumentar e diminuir de tamanho faz-nos pensar nas relações que temos com o mundo, quando nos sentimos pequenos em referência a tantas coisas e grandes perante outras. Entretanto, o princípio da identidade pressupõe que algo só pode ser o que é, ou seja, o tamanho é fixo. Como fica em nossas sensações esse princípio que afirma que cada coisa é igual a si mesma? Quantas vezes nos sentimos pequenos e inferiores? E em quantas situações nossa autoestima se eleva, dando a sensação de sermos grandes como gigantes? Isso acontece várias vezes, inclusive no mesmo dia.

Então, Alice se questiona: "Posso terminar sumindo completamente como uma vela. E como é que eu seria depois disso"?. ${ }^{2}$ Esse trecho
${ }^{2}$ As citações de trechos do livro serão destacadas e não será mencionado o número da página, pois várias traduções foram utilizadas na análise realizada. 
leva-nos a refletir a respeito da sua "identidade essencial": afinal, se ela estava se tornando menor a cada momento, por que não poderia ter um fim semelhante ao de uma vela, que desaparece após o processo? O que poderia definir o que e quem ela realmente é?

Após diminuir, Alice certificou-se de que a chave havia ficado em cima de uma mesa de vidro, muito alta, agora que ela está pequena. Ela briga consigo mesma, como se existissem duas Alices agindo de maneiras diferentes: uma apenas assistindo aos acontecimentos e a outra os vivendo; uma fazendo loucuras e a outra a repreendendo. Muitas vezes, deparamo-nos com uma espécie de conversa interior e nos perguntamos: Qual a minha natureza? Qual a minha identidade? Qual é o meu verdadeiro eu? Quem sou eu? Esses questionamentos envolvem temas filosóficos clássicos e podem ser explorados por meio dos pensamentos e das aventuras da menina.

Alice, em seguida, encontrou um pedaço de bolo, devorou-o de uma só vez e esperou para ver o que aconteceria, colocando a mão na cabeça para acompanhar o seu crescimento do ponto de vista exterior a ela mesma. Novamente, é como se fossem duas pessoas: uma crescendo e a outra analisando o crescimento. Afinal, se Alice estava crescendo, tudo nela cresceria ao mesmo tempo, e não seria possível analisar seu tamanho colocando a mão na cabeça.

No capítulo 2, "A lagoa de lágrimas", como se o autor ainda estivesse discutindo o princípio da identidade, Alice passa a comunicar-se com partes do corpo como se fossem de outras pessoas - o bolo a fez esticar tanto que, preocupada, Alice diz, olhando para os seus pés, "... e agora, quem é que vai calçar as meias e os sapatos em vocês, meus filhinhos?". Destaca-se também, neste trecho, a exploração do nonsense, quando, dentro de uma sala trancada, surge uma praia de um mar formado pelas lágrimas que Alice havia derramado no momento em que estava grande.

Após formar uma lagoa com suas lágrimas, Alice novamente se encontra com o coelho que, sempre apressado, deixa cair uma luva e um leque, provocando na protagonista algumas conjecturas interessantes que relacionamos ao princípio da identidade:

Deus! Como tudo está tudo esquisito hoje. E ontem estava tudo tão normal. Será que eu mudei durante a noite? Deixe ver: eu era a mesma quando me levantei hoje de manhã? Estou quase jurando que me sentia um pouquinho diferente. Mas se não sou a mesma, então quem é que eu sou?

Alice interiormente questiona se teria se transformado em alguma de suas amigas: "Não posso ser Mabel... além disso, ela é ela e eu sou eu". Ela tenta verificar que é a mesma e faz um exame de seus conhecimentos. Assim, procura lembrar aquilo que aprendeu na escola, mas, como não consegue lembrar-se de nada, compara-se a uma amiga que julga ter pouco conhecimento e passa até a acreditar ser realmente ela.

A discussão a respeito da identidade, que nos ajuda a compreender limites e alcances do princípio de mesmo nome, continua no capítulo 5: 
"Conselhos de uma lagarta". Ao encontrar a lagarta, esta a questiona: "Quem é você?". E Alice responde: "Nem eu mesma sei, senhora, nesse momento... eu... enfim, sei quem era quando me levantei hoje de manhã, mas acho que já me transformei várias vezes desde então." [...] "ter tantos tamanhos diferentes num dia só é muito confuso". Vemos expressos, nesse fragmento, os diferentes tamanhos, que também poderiam corresponder a diferentes idades sendo vividas simultaneamente por uma garota que cresce e diminui constantemente. Nos trechos da história em que Alice está grande, ela se sente mais velha. Assim, as confusões de idade e tamanho interferem na formação de sua identidade, que se expressa na sensação de confusão.

Outras passagens que instigam uma discussão sobre o princípio da identidade poderiam ser mencionadas. Mas o que foi exposto é suficiente para o que procuramos destacar do ponto de vista pedagógico: que $\mathrm{A}=\mathrm{A}$ é lógico, mas não é evidente. Há muitos significados possíveis; o que se revela não é a ausência de significados, mas um universo em que os sentidos proliferam (Vilela, 2009, p. 95, 97).

\section{Discussões do princípio do terceiro excluído em Alice no país das maravilhas}

O princípio do terceiro excluído é aquele que afirma que uma proposição "A" ou é verdadeira ou é falsa, e não há uma terceira possibilidade, por exemplo, de que a proposição "A" seja possível - como postula a lógica modal -; ou de que haja outros valores de verdade intermediários da proposição entre a verdade e a falsidade - como postula a lógica trivalente ou a polivalente. De fato, o princípio do terceiro excluído impõe, em relação à linguagem ordinária do dia a dia, uma limitação das diversas possibilidades de graus de certeza, e isso pode ser observado no livro de Carroll. A própria noção de proposição - hoje um conceito primitivo -, que na formulação aristotélica é definida como composta de sujeito e predicado, já indica que as regras atuam sobre uma parte específica e restrita das frases, deixando de fora toda sentença exclamativa, imperativa, os dêiticos, etc. No contexto da relação entre a lógica e a linguagem, podemos perguntar: Qual a relação entre a lógica clássica e a nossa linguagem? Sabemos que utilizar a lógica para argumentar ou para demonstrar uma sentença matemática exige o uso de regras formais do pensamento, e essa é uma parte da linguagem que empregamos no nosso cotidiano, seja nas práticas artísticas, sociais, rituais, culturais ou em outras, próprias da natureza humana.

A linguagem que utilizamos para o estudo da lógica não é exatamente um reflexo da linguagem natural do ser humano, ainda que sejam visíveis alguns traços semelhantes e maiores afinidades na argumentação. A lógica exige treino e conhecimento próprio de um profissional capacitado para interpretá-la e compreendê-la. O campo das sentenças matemáticas pode ser pensado como parte restrita e específica da linguagem natural, o que 
pode nos ajudar a entender situações de sala de aula em que uma conclusão lógica, óbvia para o professor de matemática que coloca uma pergunta, pode representar uma fonte infinita de possibilidades de prosseguimento para um aluno ainda não treinado.

É nessa relação entre lógica e linguagem que podemos pensar na poesia - e em outras manifestações artísticas - como uma expressão que escapa, geralmente, da forma lógica. Dizemos geralmente porque existem aquelas que primam justamente pelo uso da lógica, como é o caso da poesia "Ou isto ou aquilo", da poetisa e educadora Cecília Meireles. Não podemos ver este poema como uma forma poética do princípio do terceiro excluído?

Ou se tem chuva e não se tem sol,

ou se tem sol e não se tem chuva!

Ou se calça a luva e não se põe o anel ou se põe o anel e não se calça a luva!

Quem sobe nos ares não fica no chão, Quem fica no chão não sobe nos ares.

É uma grande pena que não se possa estar ao mesmo tempo em dois lugares!

Ou guardo dinheiro e não compro doce, ou compro doce e não guardo dinheiro.

Ou isto ou aquilo: ou isto ou aquilo... e vivo escolhendo o dia inteiro!

Não sei se brinco, não sei se estudo, se saio correndo ou fico tranqüilo.

Mas não consegui entender ainda qual é melhor: se é isto ou aquilo.

(Meireles, 2002, p. 38).

Ilustremos como Carroll apresenta características do princípio do terceiro excluído por meio de uma passagem do capítulo 11: "Quem roubou as tortas?".

A cena é densa e repleta de personagens: a Rainha e o Rei, o Juiz, os 12 jurados (animais e pássaros) e o Coelho, que lia a acusação de que o Valete de Copas havia roubado as tortas que a Rainha de Copas fizera e chamou a primeira testemunha: o Chapeleiro. O Rei pediu-lhe que tirasse o chapéu e o Chapeleiro afirmou: "Não é meu".

"Roubado", exclamou o Rei.

"Uso os chapéus para vendê-los, nenhum deles é meu", esclareceu inutilmente o Chapeleiro.

Nesse trecho, Carroll explora as características e o alcance do princípio do terceiro excluído. Afinal, quando o Chapeleiro diz que o chapéu não é seu, o Rei logo acredita que ele é roubado, como se não houvesse outra possibilidade e, ainda, como se a negação lógica de "não é meu" fosse 
necessariamente "é roubado", descontextualizando a situação do vendedor de chapéus, ao mesmo tempo que moraliza o princípio em discussão. Um estudo sobre o oposto de um termo ou a negação lógica poderia também ser conduzido a partir daqui, mas mantemos o foco no terceiro excluído, observando que "não cabe concluir que o oposto deve aplicar-se quando o termo não se aplica" (Shibles, 1974, p. 76).

No capítulo 12, "Depoimento de Alice", há uma passagem em que o Gato branco acusava o prisioneiro de ser o autor de uma carta, mas não estava com sua letra e nela não havia a sua assinatura. O prisioneiro negava que houvesse escrito a carta, e o rei conduzia sua argumentação na direção de acusá-lo:

Se você não assinou - disse o Rei - isso apenas torna pior a situação. Com certeza você devia ter más intenções, ou teria assinado seu nome como qualquer pessoa honesta.

Isso prova sua culpa, é claro - disse a Rainha. Portanto, cortem-lhe a...

Aqui, percebemos que uma versão do princípio do terceiro excluído aparece mais uma vez. As proposições envolvidas na disjunção seriam: OU Valete é culpado OU Valete é culpado. O Rei sustenta que o Valete é culpado OU porque não assinou a carta OU porque, se fosse inocente, a carta estaria assinada. Não haveria hipótese alguma de o Valete não a ter escrito. De fato, uma implicação $A=>B$ só é falsa, quando A for verdadeiro e B for falso. Se pensarmos na proposição A: "assinou a carta" e B: "é culpado", a implicação só será falsa caso ele não tenha assinado a carta. Mas nessa situação, e saindo dessa implicação, o rei afirma que é culpado por ser desonesto não assinar a carta. A despeito de uma interessante discussão sobre o fato desconcertante contido na implicação lógica de que um enunciado falso implica um enunciado qualquer, nesse caso, a forma lógica deixou de valer, ou seja, quando foi conveniente, o contexto passou a ser considerado.

Todos os presentes ficaram extasiados e bateram palmas para a brilhante conclusão do Rei. Alice interrompeu as palmas e disse que aquilo não provava nada, já que os versos nem haviam sido lidos. Foi feita, então, a leitura da carta. Enquanto para Alice os versos não faziam sentido algum, durante a leitura, o Rei procurava uma forma de fazer cada frase acusar o prisioneiro, manipulando a linguagem de acordo com sua compreensão ou sua intenção. Longe da verdade e da unicidade dos significados, as palavras e as frases da linguagem em cada contexto adquirem novas significações.

\section{Discussão do princípio da não contradição e da forma lógica em Alice no país das maravilhas}

Em diversas situações ao longo da história, o Gato de Chesire aparece como um interlocutor de Alice e encerra sua participação na cena, desaparecendo subitamente. No capítulo 6, por exemplo, o Gato pergunta pelo bebê, Alice lhe conta que virara um leitão e ele simplesmente desaparece. 
Enquanto Alice caminha para o lugar onde morava a Lebre de Março, o Gato reaparece para confirmar em que se transformara o bebê, e Alice lhe pede que não apareça ou suma tão de repente. Como que atendendo ao pedido da garota, o Gato vai desaparecendo lentamente da cauda até o sorriso, restando este sem rosto. Tal sorriso remete-nos a discussões filosóficas importantes, como a questão da essência e da forma lógica, que é a forma pura, sem conteúdo, típica da lógica e presente na matemática. Neste último caso, podemos pensar que a cauda e o sorriso seriam os extremos do intervalo gato, e este seria um intervalo fechado num extremo, o da cauda, e aberto no outro, o do sorriso.

A lógica valoriza a forma e não o conteúdo, pois a validade de um argumento ou silogismo não depende da verdade ou da falsidade da premissa. "Na lógica aristotélica, no entanto, há uma separação total entre a forma e o conteúdo de uma argumentação: não são considerados os conteúdos das sentenças componentes de um argumento, mas apenas a forma de articulá-las ou o modo como uma é deduzida da outras" (Machado, Cunha, 2005, p. 14).

A lógica matemática ou simbólica distanciou-se desse problema da separação entre forma e conteúdo, na medida em que se desenvolveu de modo independente dos conteúdos das proposições, considerando-as termos primitivos e simbolizando-as, geralmente, por letras minúsculas p, q, r, s, etc. ${ }^{3}$ Para esclarecer o tema da forma lógica, tomamos silogismos em trechos do livro em análise.

Um silogismo é composto por três proposições: a premissa maior, a premissa menor e a conclusão. As premissas são compostas de três termos, os extremos e o termo médio; este último liga as duas premissas e deve ser universal, pelo menos uma vez. Seguindo as regras, o silogismo conduz a uma conclusão válida, menos extensa que as premissas. Se as premissas forem verdadeiras, chega-se, sempre, a conclusões verdadeiras. Porém, o silogismo pode ser válido com premissas falsas, isto é, a validade depende da relação entre as proposições e não da veracidade destas. Retomaremos cada uma das passagens acima com exemplos.

A estrutura de um silogismo pode ser escrita como:

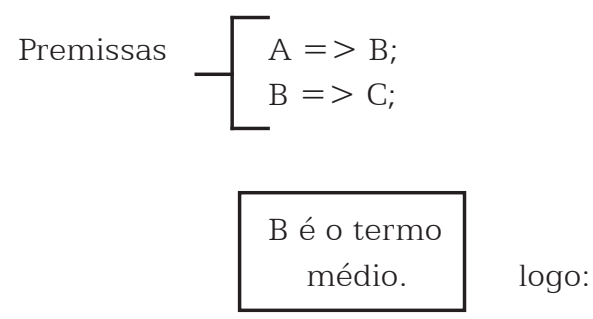

Conclusão: $\mathrm{A}=>\mathrm{C}$.

Tomamos, para ilustrar o silogismo, um trecho em que, caminhando

3 Existem estudos específicos que relacionam lógica e argumentação. Ver Epistein (1999). mostrar à menina a sua canção, mas a Rosa impôs que, juntas, cantassem pelo bosque, Alice conversa com as flores. Cada espécie de flor queria 
a canção das flores. Alice senta em uma folha e ouve tudo atentamente, participando no final da música. Eis que, então, elas começaram a questionar Alice sobre suas características, que não eram correspondentes às de nenhuma outra flor: "Suas pétalas são de cor muito diferente; ela não exala nenhum perfume e olhe os caules, muito fininhos!".

Poderemos sugerir a construção de silogismos, utilizando proposições correspondentes às afirmações citadas.

1) Toda flor tem pétalas de cores comuns.

Alice tem pétalas de cores incomuns.

Logo, Alice não é uma flor.

Simbolicamente:

$\mathrm{A}=>\mathrm{B}$ Regra de dedução:

$\neg$ B (Alice) Modus tollens

$\neg$ A (Alice não é uma flor)

Nesse caso, o termo médio é "pétalas com cores incomuns", que liga as duas premissas e não aparece na conclusão. Outro silogismo que usa a mesma regra de dedução seria:

Toda flor exala perfume.

Alice não exala perfume.

Logo, Alice não é uma flor.

A regra usada aqui ficou conhecida a partir da Idade Média como modus tollens ou modus tollendo ponens, expressão latina que significa modo de afirmar negando. A outra regra denominou-se modus ponens ou modus ponendo ponens, também expressão latina, que quer dizer modo de afirmar afirmando e, simbolicamente, assim se escreve:

$\mathrm{A}=>\mathrm{B} \quad$ Regra de dedução:

A Modus ponens

B

A partir das conclusões obtidas dedutivamente, e somando-se a isso o fato de Alice assumir ser uma garota, as flores a expulsaram do jardim e ela continuou sua caminhada.

Para ilustrar especificamente a forma lógica do silogismo, apresentamos dois exemplos de argumento válido e premissa falsa:

1) Todos os metais são sólidos.

Mercúrio é um metal.

Logo, mercúrio é sólido! 
2) Todos os cavalos são macacos.

Todos os macacos são cachorros.

Todos os cavalos são cachorros.

Não identificamos no livro de Carroll a forma lógica do silogismo mencionada acima, mas falácias e paradoxos serão apresentados em seguida mediante um trecho da história em que a Pomba confunde Alice com uma serpente. Uma falácia implica um argumento não válido quando há erro na inferência lógica, erro na regra de dedução, e tampouco depende da veracidade da premissa: depende somente da forma. As falácias formais ${ }^{4}$ podem ser de ambiguidade, quando há vários sentidos associados a termos presentes nas premissas ou petição de princípio - tanto a premissa quanto a conclusão afirmam a mesma coisa -, também conhecida como argumento circular ou círculo vicioso (que carrega como pressuposto o que pergunta ou define). Sobre o último, mencionamos uma definição viciosa de "tartaruga falsa" que se destaca pela brincadeira proposta pelo autor, já que "sopa de tartaruga falsa" seria o nome de uma sopa que não inclui tartaruga entre os ingredientes. A Rainha pediu a Alice que a levasse até a falsa tartaruga. Alice diz: "Nem sei o que seja uma falsa tartaruga". A Rainha responde: "É aquilo de que se faz sopa de tartaruga falsa!". O autor utiliza, além de um jogo de palavras que envolve tartaruga falsa, sopa de tartaruga falsa, sopa falsa, a tristeza da tartaruga falsa, a tristeza falsa, etc, um argumento circular; ou seja, não se trata de uma definição coerente.

Ilustramos a falácia por uma das situações da história em que Alice muda de tamanho: cresceu tanto que seu pescoço tinha capacidade de movimentar-se em qualquer direção, como uma serpente. Foi quando uma grande pomba veio ao seu encontro e começou a bicá-la. A pomba iniciou uma discussão com Alice, acusando-a de ser uma serpente, apesar de a menina negar. A pomba pergunta: "Você é o quê?". E Alice responde: "Eu sou uma menina". A pomba diz, então: "[...] Já vi uma porção de meninas na minha vida, mas nunca vi uma com pescoço tão grande! Não, não! Você é uma serpente, não adianta negar isso!".

Silogismo:

Toda serpente tem pescoço grande.

Alice tem pescoço grande.

Logo, Alice é uma serpente.

A: Ser serpente.

B: Ter pescoço grande.

Simbolicamente:

$\mathrm{A}=>\mathrm{B}$ Regra de dedução:

B Modus Polens com erro

${ }^{4}$ Ver Machado e Cunha (2005).

A 
A afirmação "se é serpente, tem pescoço grande" não quer dizer que "se tem pescoço grande, é serpente".

Ou seja,

$$
\mathrm{A}=>\mathrm{B}
$$

mas B não $=>$ A.

O princípio da não contradição veta que uma proposição seja, ao mesmo tempo, verdadeira e falsa. Se ocorrer, num sistema de proposições, que a mesma sentença seja afirmada e negada $[A \wedge \neg \mathrm{A}]$, haverá um paradoxo.

Os paradoxos estão presentes na obra de Carroll e ajudam-nos a entender o princípio da não contradição. No capítulo 8, "O campo de críquete da rainha", estava em cena um cortejo de cartas de baralho e surgiram o Rei e a Rainha de Copas, que exerciam seu poder punindo seus súditos por meio da ordem que aparece de forma recorrente na história: Cortem-lhes as cabeças! Mais do que um massacre coletivo, essa ordem parece uma maneira de a Rainha expor suas sensações de ira, assim como de impor sua autoridade. No entanto, o que nos interessa, neste momento, é salientar o paradoxo que há em querer cortar a cabeça de cartas de baralho, que não têm cabeça, e de um gato que, nesta cena, só tem a cabeça.

E isso, de fato, gerou problemas práticos. Quando Alice estava voltando para sua conversa com o Gato, surgiu uma multidão de pessoas com suas opiniões a respeito de como agir com ele: o Carrasco dizia que nunca havia cortado uma cabeça sem corpo, o Rei afirmava que tudo que tinha cabeça poderia ser decapitado e a Rainha ameaçava decapitar todos ao redor.

Nesse trecho, há paradoxos interessantes que podem ser trabalhados no estudo de lógica, como o ponto de vista do Carrasco que deveria decapitar o Gato Chesire, que não tinha corpo, somente a cabeça. Mas, como decapitar é arrancar a cabeça, a contradição se instala quando se coloca a questão: de onde arrancá-la? Mas, se ordenasse que fossem decapitados todos ali, ela, a Rainha, também seria decapitada. E o paradoxo não termina aí, pois o Carrasco teria que se decapitar. Essa seria uma referência indireta ao conhecido Paradoxo de Russe $l^{5}$ ou seria outra forma de expressão desse paradoxo?

Em termos da lógica clássica formal, o sorriso sem rosto pode também ser uma ilustração de uma contradição no sentido lato, já que, para existir sorriso, é necessário que exista uma boca, um rosto. De fato, a definição de sorriso encontrada no dicionário Aurélio é: "ligeira contração dos músculos faciais" ou "movimento ou expressão de um rosto". Quando permanece o sorriso e não há rosto, a definição não mais se sustenta. O sorriso sem rosto "é" e, ao mesmo tempo, pela definição, "não é"; portanto, contraria o princípio da lógica clássica, que afirma que "algo não pode ser e não ser ao mesmo tempo".

\footnotetext{
5 Paradoxo de Russel em linguagem da Teoria de Conjuntos: $\mathrm{R}:\{\mathrm{x}$ t 1 que $\mathrm{x}$ não pertence a $\mathrm{x}\}$; no caso, $\mathrm{R}=$ todos os carrascos que não se matam. Se x não se mata, então ele pertence a $\mathrm{R}$, mas isso gera contradição, porque os elementos de $\mathrm{R}$ são aqueles que se matam.
} 
O tema da forma sem conteúdo traz ainda a questão da essência do ser. Desaparecendo as propriedades físicas de um ser, não lhe restaria a essência? Eis uma questão filosófica que pode ser entendida como apresentada pelo autor simbolicamente por um sorriso sem rosto.

\section{Considerações finais}

Destacamos, inicialmente, o potencial do livro Alice no país das maravilhas para encaminhar uma reflexão sobre o desenvolvimento do raciocínio lógico proposto para estudantes de diversos níveis de ensino, considerando os conceitos de lógica que podem ser estudados no contexto da obra e são apresentados por meio das aventuras de Alice e dos personagens que conviveram com a menina nesse seu mundo de sonhos e fantasias.

Utilizando-se de um roteiro supostamente infantil, Carroll permeia a história com temas da lógica, dos quais alguns foram explorados neste estudo: os três princípios básicos da lógica clássica - o da identidade, o da não contradição e o do terceiro excluído -, a ideia da forma lógica, as regras de dedução e a estrutura do silogismo. Além disso, algumas questões clássicas da filosofia são salientadas no contexto da história, como os temas da essência, do conhecimento e do ser.

No decorrer do artigo, procuramos realçar que o objetivo de desenvolver o raciocínio lógico da criança deve ser considerado no contexto de sua formação integral, ou seja, deve ser apreciado tanto quanto o desenvolvimento de aspectos sociais, culturais, psicológicos, físicos e emocionais. A criança deve ser considerada um ser completo e não mais, como já se acreditou, um adulto pequeno, em crescimento (Arroyo, 1995).

Destacamos, ainda, que o desenvolvimento do raciocínio lógico não é uma construção natural: deve ser apreendido, especificamente, numa situação escolar. Não responder logicamente indica que aquilo ainda não foi apreendido, e não que haja necessariamente problemas de desenvolvimento cognitivo. Além disso, a dedução contém em si a conclusão, isto é, no raciocínio lógico há um desdobramento, e não a criação de um novo conhecimento.

Assim, consideramos importante o potencial deste artigo para professores ou futuros professores, tanto de matemática quanto das séries iniciais do ensino fundamental e da educação infantil, por despertar o pensamento filosófico e questões sobre temas que parecem óbvios. Concluímos, portanto, que este estudo permite uma série de reflexões interessantes sobre o pensamento lógico e estimula um trabalho educacional consciente com o raciocínio lógico, exercido conjuntamente com a criatividade e a imaginação da criança.

A história que se passa dentro de um universo infantil em que a fantasia predomina, intermediada pela presença de uma série de conceitos de lógica, possibilita-nos percorrer os limites da lógica e da linguagem, no mundo da argumentação e da fantasia criado no sonho de Alice, e alcançar, assim, uma ideia de como seria o país das maravilhas. 


\section{Referências bibliográficas}

ARROYO, M. G. O significado da infância. Criança, Brasília, n. 28, p. 17-21, 1995.

BRASIL. Ministério da Educação e do Desporto (MEC). Secretaria de Educação Fundamental. Parâmetros Curriculares Nacionais Ensino Fundamental. Brasília: MEC/SEF, 1998a.

. Referenciais Curriculares Nacionais para a Educação Infantil.

Brasília: MEC/SEF, 1998b.

CARROLL, Lewis. Aventuras de Alice no país das maravilhas; Através do espelho e o que Alice encontrou lá. São Paulo: Summus, 1980.

. Alice no país das maravilhas [Alice's Adventures in Wonderland]. Disponível em: <http://fenrisulfr.multiply.com/reviews/item/9>. Acesso em: 16 jun. 2009.

CHERVEL, André. História das disciplinas escolares: reflexões sobre um campo de pesquisa. Teoria \& Educação, Porto Alegre, n. 2, p. 177-229, 1990.

COSTA, Newton da. Pequena história da lógica contemporânea. Folha de São Paulo, São Paulo, p. 4, ago. 2002.

DORTA, Deizieli A. Um estudo sobre a lógica matemática no livro Alice no país das maravilhas. Trabalho de Conclusão de Curso (Licenciatura Plena em Matemática) - Universidade Federal de São Carlos (UFSCar), São Carlos-SP, 2009.

D'OTTAVIANO, Ítala Maria L.; FEITOSA, Hércules de Araújo. Sobre a história da lógica, a lógica clássica e o surgimento das lógicas não clássicas. Disponível em: <ftp://ftp.cle.unicamp.br/pub/arquivos/ educacional/ArtGT.pdf>. Acesso em: 15 jun. 2009.

EPSTEIN, R. Critical thinking. Wadsworth: Belmont, 1999.

FREGE, G. Os fundamentos da Aritmética. São Paulo: Abril Cultural, 1983.

GOTTSCHALK, Cristiane M. A construção e transmissão do conhecimento matemático sob uma perspectiva wittgensteiniana. Cadernos Cedes, Campinas, v. 28, n. 74, p. 75-96, jan./abr. 2008.

MACHADO, Nilson J.; CUNHA, Marisa O. Lógica e linguagem cotidiana: verdade, coerência, comunicação, argumentação. Belo Horizonte:

Autêntica, 2005. 
MEIRELES, Cecília. Ou isto ou aquilo. Rio de Janeiro: Nova Fronteira, 2002.

PINTO, Gabriel Faria Soares. Análise filosófica da obra Alice no país das maravilhas. Disponível em: < http://www.ump.edu.br/midialogos/ed_02/ ensaios/Analise\%20Filosofica.pdf>. Acesso em: 16 jun. 2009.

SHIBLES, Warren. Wittgenstein, linguagem e filosofia. São Paulo: Cultrix; Usp, 1974.

VILELA, Denise S. Análise das críticas de Frege a Cantor: a noção de número e o emprego da abstração nas definições. 1996, 124 f. Dissertação (Mestrado) - Instituto de Filosofia e Ciências Humanas, Universidade Estadual de Campinas (Unicamp), Campinas-SP, 1996.

Reflexão filosófica acerca dos significados matemáticos nos contextos da escola e da rua. In: KLUTH, V.; ANASTÁCIO, M. Q. (Orgs.). Filosofia da educação matemática: debates e confluências. São Paulo: Centauro, 2009. p. 81-99.

WITTGENSTEIN, Ludwig. Investigações filosóficas. São Paulo: Abril Cultural, 1991. (Os Pensadores).

Denise Silva Vilela, doutora na área de Educação Matemática pela Universidade Estadual de Campinas (Unicamp), é docente do Departamento de Metodologia de Ensino e do Programa de Pós-Graduação em Educação da Universidade Federal de São Carlos (UFSCar).

denisevilela@ufscar.br

Deiziele Dorta, licenciada em Matemática pela Universidade Federal de São Carlos (UFSCar), é professora da educação infantil na rede municipal de Pirassununga, São Paulo.

deiziii@hotmail.com

Recebido em 9 de março de 2010.

Aprovado em 16 de setembro de 2010. 